\title{
Integrated sequencing and array comparative genomic hybridization in familial Parkinson disease
}

Laurie A. Robak, MD, PhD, * Renqian Du, PhD, DDS, * Bo Yuan, PhD, Shen Gu, PhD, Isabel Alfradique-Dunham, MD, Vismaya Kondapalli, BS, Evelyn Hinojosa, BS, Amanda Stillwell, BS, Emily Young, BA, Chaofan Zhang, BS, Xiaofei Song, PhD, Haowei Du, MS, Tomasz Gambin, PhD, Shalini N. Jhangiani, PhD, Zeynep Coban Akdemir, PhD, Donna M. Muzny, MS, Anusha Tejomurtula, MS, Owen A. Ross, PhD, Chad Shaw, PhD, Joseph Jankovic, MD, Weimin Bi, PhD, Jennifer E. Posey, MD, PhD, James R. Lupski, MD, PhD, † and Joshua M. Shulman, MD, PhD†

Neurol Genet 2020;6:e498. doi:10.1212/NXG.0000000000000498

\section{Abstract}

\section{Objective}

To determine how single nucleotide variants (SNVs) and copy number variants (CNVs) contribute to molecular diagnosis in familial Parkinson disease (PD), we integrated exome sequencing (ES) and genome-wide array-based comparative genomic hybridization (aCGH) and further probed CNV structure to reveal mutational mechanisms.

\section{Methods}

We performed ES on 110 subjects with PD and a positive family history; 99 subjects were also evaluated using genome-wide aCGH. We interrogated ES and aCGH data for pathogenic SNVs and CNVs at Mendelian PD gene loci. We confirmed SNVs via Sanger sequencing and further characterized CNVs with custom-designed high-density aCGH, droplet digital PCR, and breakpoint sequencing.

\section{Results}

Using ES, we discovered individuals with known pathogenic SNVs in GBA (p.Glu365Lys, p.Thr408Met, p.Asn409Ser, and p.Leu483Pro) and LRRK2 (p.Arg1441Gly and p.Gly2019Ser). Two subjects were each double heterozygotes for variants in GBA and LRRK2. Based on aCGH, we additionally discovered cases with an SNCA duplication and heterozygous intragenic GBA deletion. Five additional subjects harbored both SNVs (p.Asn52Metfs*29, p.Thr240Met, p.Pro437Leu, and p.Trp453*) and likely disrupting CNVs at the PRKN locus, consistent with compound heterozygosity. In nearly all cases, breakpoint sequencing revealed microhomology, a mutational signature consistent with CNV formation due to DNA replication errors.

\section{Conclusions}

Integrated ES and aCGH yielded a genetic diagnosis in $19.3 \%$ of our familial PD cohort. Our analyses highlight potential mechanisms for SNCA and PRKN CNV formation, uncover multilocus pathogenic variation, and identify novel SNVs and CNVs for further investigation as potential PD risk alleles.

\author{
Correspondence \\ Dr. Shulman \\ Joshua.Shulman@bcm.edu \\ or Dr. Lupski \\ jlupski@bcm.edu
}

\footnotetext{
*These authors contributed equally to this manuscript as co-first authors.

tThese authors contributed equally to this manuscript as co-last authors.

From the Department of Molecular and Human Genetics (L.A.R., R.D., B.Y., S.G., V.K., E.H., A.S., E.Y., C.Z., X.S., H.D., T.G., Z.C.A., A.T., C.S., W.B., J.E.P., J.R.L., J.M.S.), Department of Neurology (I.A.-D., J.J., J.M.S.), and Human Genome Sequencing Center (S.N.J., D.M.M., J.R.L.), Baylor College of Medicine, Houston, TX; Baylor Genetics (W.B.), Houston, TX; Department of Neurology (O.A.R.), Department of Neuroscience (O.A.R.), and Department of Clinical Genomics (O.A.R.), Mayo Clinic, Jacksonville, FL; Parkinson's Disease Center and Movement Disorders Clinic (J.J.) and Department of Pediatrics (J.R.L., J.M.S.), Baylor College of Medicine, Houston, TX; Department of Pediatrics (J.R.L.), Texas Children's Hospital, Houston; Department of Neuroscience (J.M.S.), Baylor College of Medicine, Houston, TX; and Jan and Dan Duncan Neurological Research Institute (J.M.S.), Texas Children's Hospital, Houston.

Go to Neurology.org/NG for full disclosures. Funding information is provided at the end of the article. 


\section{Glossary}

aCGH = array-based comparative genomic hybridization; BCM = Baylor College of Medicine; $\mathbf{C N V}=$ copy number variant; ddPCR = droplet digital PCR; DUP-TRP/INV-DUP = duplication-inverted triplication-duplication; ES = exome sequencing; FoSTeS = fork stalling and template switching; MMBIR = microhomology-mediated break-induced replication; OR = odds ratio; PD = Parkinson disease; SNV = single nucleotide variant; VUS = variant of unknown significance.

Up to $20 \%$ of patients with Parkinson disease (PD) report a positive family history, ${ }^{1}$ and genetic risk factors are more common in these families. ${ }^{2}$ Identification of specific genetic risk factors can reveal prognostic information, such as risk of cognitive impairment and/or rate of progression, and may soon highlight eligibility for personalized therapies. ${ }^{3}$ In addition, discovery of risk variants may inform genetic counseling of unaffected family members. Indeed, surveys of patients with PD and caregivers reveal a high level of interest in genetic testing for PD. ${ }^{4}$

More than 40 different loci that increase PD susceptibility have been identified in familial and sporadic PD. ${ }^{5,6}$ Exome sequencing (ES) is ideally suited to identify single nucleotide variants (SNVs) in genetically heterogeneous diseases. In a study of adult patients referred for diverse clinical indications, ES had a diagnostic yield of $10 \%$ in individuals older than 30 years. ${ }^{7}$ In a recent study of 80 early-onset sporadic PD cases, ES yielded an overall diagnostic rate of $11 \%$, with GBA alleles accounting for $5 \%{ }^{8}$ Nevertheless, clinical genetic testing is not routinely performed for PD, and ES remains poorly studied as a potential genetic diagnostic tool.

Although most identified PD risk alleles are SNVs, chromosomal structural rearrangements, or copy number variants (CNVs), also play an important role. ${ }^{9}$ Despite notable recent advances, ${ }^{10} \mathrm{ES}$ remains insensitive for detection of small CNVs $(<50 \mathrm{~kb}) .{ }^{11}$ Several complementary approaches, including multiplex ligation-dependent probe amplification, bacterial artificial chromosome arrays, and single nucleotide polymorphism arrays, ${ }^{12,13}$ have shown mixed success for identification of CNVs in PD cohorts. In contrast, genomewide array-based comparative genomic hybridization (aCGH) is a highly-validated, sensitive clinical screening tool for $\mathrm{CNV}$ detection, offering exon-by-exon coverage for a multitude of disease-associated genes. ${ }^{14,15}$ Although not yet adopted in most diagnostic laboratories, droplet digital PCR (ddPCR) is also emerging as a rapid and cost-efficient, targeted approach for the assessment of small CNVs at specific loci. Compared with standard quantitative PCR, digital PCR offers enhanced copy number and gene dosage sensitivity, precision, and reliability due to sample partitioning. ${ }^{16}$ In addition, mechanisms of CNV formation in PD remain understudied.

To our knowledge, integrated ES and aCGH for analysis of SNVs and CNVs, respectively, have not previously been systematically used in PD. We hypothesized that ES and aCGH in combination will yield an increased genetic molecular diagnostic rate. We also evaluated ddPCR as a novel strategy for confirmation of pathogenic CNVs in $\mathrm{PD}$, and using breakpoint sequencing, we investigated potential mechanisms for $\mathrm{CNV}$ formation.

\section{Methods}

See supplementary information (links.lww.com/NXG/A305) for complete methods, including further details and references.

\section{Subjects}

We studied 110 PD cases evaluated in the Baylor College of Medicine (BCM) PD Center and Movement Disorders Clinic in Houston, TX, with a family history of PD. As a positive control for aCGH, we included a sample from a known subject with an SNCA triplication. ${ }^{17-19}$ We also interrogated a Baylor Genetics diagnostic laboratory sample including 12,922 clinical referral samples for aCGH from peripheral blood using either v9 or v10 Baylor arrays. Subject numbers throughout the text are consistent with clinical and demographic details provided in table e-1 (links.lww.com/ NXG/A306).

\section{Standard protocol approvals, registrations, and subject consents}

All subjects provided informed consent. The BCM Institutional Review Board approved this study along with the analysis of aggregate clinical genomic data.

\section{Gene set definition and variant criteria}

We focused our analyses on genes and variants established to cause familial PD, including the autosomal dominant loci, SNCA (PARK1, MIM\#168601), GBA (MIM\#168600), LRRK2 (MIM\#607060), GCH1 (MIM\#600225), DNAJC13 (MIM\#616361), and VPS35 (MIM\#614203), as well as the autosomal recessive loci, PRKN (PARK2, MIM\#600116), PINK1 (MIM\#605909) and PARK7 (DJ1, MIM\#606324), based on the available literature in April 2015 when this study was initiated. ${ }^{5,6}$ In our $\mathrm{CNV}$ analyses, we also considered deletions at 22q11.2. Gene names in this study conform to current guidelines from the HUGO Gene Nomenclature Committee (genenames.org). All pathogenic alleles included in this study are well-established, nonsynonymous coding variants with moderate to high penetrance (odds ratio [OR] $>2$ ) meeting stringent evidence for replication across studies or within the same study. We considered all other variants discovered in these genes but not previously reported in PD to be variants of unknown significance (VUSs). 
Detection and confirmation of SNVs and CNVs We extracted genomic DNA from peripheral blood samples obtained from each participant and performed ES using the Illumina HiSeq 2000 at the BCM Human Genome Sequencing Center. Samples achieved an average of $95 \%$ of targeted exome bases covered to a depth of $20 \mathrm{X}$ or greater. All pathogenic SNVs detected were confirmed via Sanger sequencing. Genome-wide array CGH was performed on 99 of 110 subjects for which sufficient DNA remained using Baylor Genetics v10 2x400K clinicalgrade oligonucleotide microarrays. We defined potential $\mathrm{CNVs}$ as those regions with 3 or more consecutive probes with consistent direction of effect. For confirmation, we used a custom $8 \times 60 \mathrm{~K}$ high-density array through Agilent (Santa Clara, CA). To confirm CNVs at $P R K N$ and GBA, we additionally performed ddPCR (see e-Methods for detailed protocol, links.lww.com/NXG/A305).

\section{Data availability}

For all subjects in the BCM cohort who consented to allow for public data sharing, ES and aCGH are in process for release in relevant genomic databases. The complete ES and aCGH data sets are also available on request by contacting the corresponding author, Dr. Shulman (joshua.shulman@bcm.edu).

\section{Results}

We pursued genetic diagnostic evaluation of 110 total subjects (including 109 unrelated probands) with familial PD. The mean age at onset was 50 years $(\mathrm{SD}=15) ; 51 \%$ were male. The ethnic composition of the cohort was $72 \%$ Caucasian, 17\% Hispanic, 6\% East Asian, South Asian or Middle Eastern, and $6 \%$ undefined (not reported).

\section{Single nucleotide variants}

We first examined subject ES data for pathogenic SNVs in established PD genes (see Methods). Among the dominant PD loci, 15 individuals had variants in LRRK2 (c.6055G>A:p.Gly2019Ser and c.4321C>G:p.Arg1441Gly) and GBA (c.1093G>A:p.Glu365Lys, c.1223C>T: p.Thr408Met, c.1448T>C:p.Leu483Pro, and c.1226A>G: p.Asn409Ser) (table 1 and table e-1, links.lww.com/ NXG/A306). Two subjects each harbored heterozygous SNVs in both $G B A$ and $L R R K 2$, i.e., were double heterozygotes. One such subject had a combination of LRRK2 p.Gly2019Ser and GBA p.Glu365Lys (subject 2), whereas the other had LRRK2 p.Gly2019Ser and GBA p.Leu483Pro (subject 13). Both subjects had onset of PD symptoms in their 40s. On initial examination, subject 2 had tremor at rest, rigidity, bradykinesia, and dystonic posturing in both hands. She reported a history of PD in her father and paternal grandfather (figure e-1A, links.lww.com/NXG/ A305, and table e-1, links.lww.com/NXG/A306). There was no history of cognitive impairment or dementia. Subject 13 presented with resting tremor, rigidity, and bradykinesia. She reported a family history of $\mathrm{PD}$ in her paternal uncle (figure e-1B, links.lww. com/NXG/A305, and table e-1, links.lww.com/NXG/A306). Ten years after PD diagnosis, she developed visual hallucinations and delusions. The subjects were of European and Hispanic ancestry, respectively; neither reported Ashkenazi Jewish heritage.
ES also revealed 7 individuals with pathogenic variants in loci usually associated with autosomal recessive $\mathrm{PD}$, including $P R K N$ (6 individuals) and PARK7 (1 individual). However, all subjects were heterozygous SNV carriers, and therefore, isolated ES was nondiagnostic (table 1). Therefore, based on ES alone, we identified a pathogenic variant accounting for PD in 13.8\% ( $\mathrm{n}=$ 15 of 109 probands) of our familial PD cohort. We confirmed all implicated variants via Sanger sequencing. Besides the pathogenic variants noted above, ES also identified heterozygous VUSs in many PD risk genes (table e-2, links.lww.com/NXG/A306).

\section{Copy number variants}

We next interrogated aCGH data for pathogenic $\mathrm{CNVs}$ among PD genes. Our analyses included 99 of 110 total subjects evaluated by ES. We did not detect any CNVs in VPS35, LRRK2, DNAJC13, GCH1, PARK7, or PINK1, nor did we identify any candidate deletions at the 22q11.2 locus. However, we discovered CNVs in SNCA ( $\mathrm{n}=1), \mathrm{GBA}(\mathrm{n}=$ $1)$, and PRKN ( $\mathrm{n}=5)$. We confirmed all reported CNVs through custom high-density arrays and breakpoint sequencing. CNVs in SNCA and GBA affect dominant PD genes and were therefore diagnostic based on aCGH alone. We consider all heterozygous CNVs in the recessive PD gene, $P R K N$, in combination with ES results (see next section). Overall, isolated aCGH identified a diagnostic genetic risk factor for PD in $2.0 \%$ of our cohort ( $n=2$ of 99 probands). Based on aCGH, we also detected numerous large $\mathrm{CNVs}(>1$ $\mathrm{Mb}$ ) within our cohort that affect other genomic loci; these variants remain of uncertain clinical significance (table e-3, links.lww.com/NXG/A306).

In subject 3 , we detected a 248 -kb duplication encompassing SNCA, as well as the adjacent gene, MMRN1. We confirmed this CNV by high-density aCGH and breakpoint analysis (figure 1A). On initial examination, this subject exhibited rigidity, tremor, and gait impairment, along with hyperreflexia and clonus. The subject was of Hispanic and Native American ancestry; the subject's father had PD with dementia. Besides providing independent confirmation, breakpoint sequencing can provide clues to mechanisms of CNV formation. In the case of subject 3, we identified a 1-bp microhomology domain, which is a short sequence that is identical to another region in the genome reduced from 2 copies to 1 during the template switch accompanying replicative repair. ${ }^{20}$ Microhomology is characteristic of certain DNA replication errors that can generate CNVs (see Discussion). ${ }^{21,22}$ As a positive control for our aCGH analysis, we also included a known SNCA triplication sample from the index family in which SNCA locus multiplication was first discovered as a cause for PD. ${ }^{17-19}$ Breakpoint sequencing revealed that this copy number alteration is a 1.7$\mathrm{Mb}$ complex genomic rearrangement (figure $1 \mathrm{~B}$ ), consisting of a duplication-inverted triplication-duplication (DUPTRP/INV-DUP). This finding confirms and extends prior investigation of this particular structural variant ${ }^{23}$ and is also consistent with a likely replication-based mechanism for $\mathrm{CNV}$ formation. ${ }^{24}$ 
Table 1 SNVs associated with increased PD risk detected via exome sequencing

\begin{tabular}{|c|c|c|c|}
\hline Gene & Variant & Diagnostic & Subjects $(n)$ \\
\hline \multicolumn{4}{|c|}{ Dominant } \\
\hline LRRK2 & c.6055G>A:p.Gly2019Ser & Y & $3^{a, b}$ \\
\hline LRRK2 & c.4321C>G:p.Arg1441Gly & Y & 1 \\
\hline$G B A$ & c.1093G>A:p.Glu365Lys & Y & $5^{a}$ \\
\hline$G B A$ & c.1223C>T:p.Thr408Met & $\mathrm{Y}$ & 5 \\
\hline$G B A$ & c.1448T>C:p.Leu483Pro & Y & $1^{\mathrm{b}}$ \\
\hline$G B A$ & c.1226A>G:p.Asn409Ser & $\mathrm{Y}$ & 2 \\
\hline \multicolumn{4}{|c|}{ Recessive } \\
\hline PRKN & c.155delA:p.Asn52Metfs*29 & $Y^{*}$ & 1 \\
\hline PRKN & c.1310C>T:p.Pro437Leu ${ }^{c}$ & $Y^{*}$ & 1 \\
\hline PRKN & c.1358G>A:p.Trp453* & $Y^{*}$ & 1 \\
\hline PRKN & c.719C>T:p.Thr240Met & $Y^{*}$ & 2 \\
\hline PRKN & c.823C>T:p.Arg275Trp & $N$ & 1 \\
\hline PARK7 & c.310G>A:p.Ala104Thr & $\mathrm{N}$ & 1 \\
\hline \multicolumn{4}{|c|}{$\begin{array}{l}\text { Abbreviations: CNV = copy number variant; PD = Parkinson disease; SNV = single nucleotide variant. } \\
\text { All indicated SNVs were heterozygous, except } P R K N \text { c.719C>T:p.Thr240Met, which was hemizygous, as the variant is in trans to a deletion allele. Pathogenic } \\
\text { variants were considered diagnostic (Y) if discovered in an autosomal dominant gene, or in the case of autosomal recessive genes, if in combination with a } \\
\text { CNV (asterisk, see also figure 3). Nondiagnostic (N), heterozygous SNVs were also discovered in PRKN (p.Arg275Trp) and PARK7 (p.Ala104Thr). In } 2 \text { subjects, } \\
\text { SNVs in both LRRK2 and GBA were identified (double heterozygotes). } \\
\text { a LRRK2 p.Gly2019Ser and GBA p.Glu365Lys. } \\
\text { b LRRK2 p.Gly2019Ser and GBA p.Leu483Pro. } \\
\text { ' Interpretations of c.1310C>T:p.Pro437Leu are conflicting (see e-References, links.lww.com/NXG/A306). }\end{array}$} \\
\hline
\end{tabular}

We also discovered a heterozygous intragenic deletion in GBA in 1 subject (figure 2), who presented at age 28 years with tremor, bradykinesia, and rigidity. She had an excellent response to levodopa in her early 30 s and subsequently developed dyskinesia. The subject was of European descent, and both of her maternal grandparents were also diagnosed with PD (figure e-1C, links.lww.com/NXG/A305). Because variant confirmation at the GBA locus can be complicated by an adjacent pseudogene with significant homology, we confirmed the $4.7-\mathrm{kb}$ deletion of exons $2-8$ using long-range PCR. Using breakpoint sequencing, we also confirmed heterozygosity and further revealed a 5-bp microhomology domain consistent with $\mathrm{CNV}$ formation due to nonhomologous recombination or replication errors (figure $2 \mathrm{~B}$ ).

\section{Integrated analysis of SNVs and CNVs}

As highlighted above, isolated ES and aCGH each identified a number of subjects with heterozygous SNVs or CNVs affecting recessive genes. To determine whether these changes might be diagnostic, we next examined the results together for potential biallelic variation due to both an SNV allele and a $\mathrm{CNV}$ allele. Indeed, 3 subjects in our cohort were newly identified as potential compound heterozygous carriers of both a pathogenic CNV and SNV in PRKN (figure 3). Subject 6 had a 364-kb duplication of exons 4-6 and a frameshift deletion c.155delA:p.Asn52Metfs*29. Subject 20 had a 222-kb deletion of exons 8 and 9 and a stopgain c.1358G $>A$ : p.Trp453*. Subject 11 harbored a pathogenic PRKN SNV (c.1310C>T:p.Pro437Leu) and a complex locus rearrangement, including a copy number neutral region flanked by $404 \mathrm{~kb}$ and $199 \mathrm{~kb}$ duplications affecting exons 2 and 3 and exons 5 and 6, respectively (figure 3B). Our cohort also included 2 brothers with known PRKN-PD ${ }^{25}$; however, neither ES nor aCGH was previously performed on these subjects. Our analysis confirmed compound heterozygosity for the known pathogenic SNV in exon 6 (c.719C >T:p.Thr240Met, apparently homozygous on ES) and a CNV (178-kb deletion of exons 5 and 6) (figure 3C). Of interest, ES also discovered an additional VUS (c.2T>C:p.Met1Thr). Based on available clinical information (table e-1, links.lww.com/NXG/A306), all subjects with $P R K N$ variants had young-onset PD (age range $15-36$ years).

We again confirmed all CNVs using custom, high-density arrays as well as breakpoint sequencing. In the case of subject 6 , we were unable to successfully amplify breakpoint junctions despite multiple attempts, suggesting a more complex genomic rearrangement or raising the possibility that this duplication is located elsewhere in the genome. For all other PRKN CNVs, figure 3 shows the junction structures, highlighting likely mechanisms of CNV formation. Overall, integrated ES and $\mathrm{CNV}$ identified a genetic cause for PD in 4 additional 


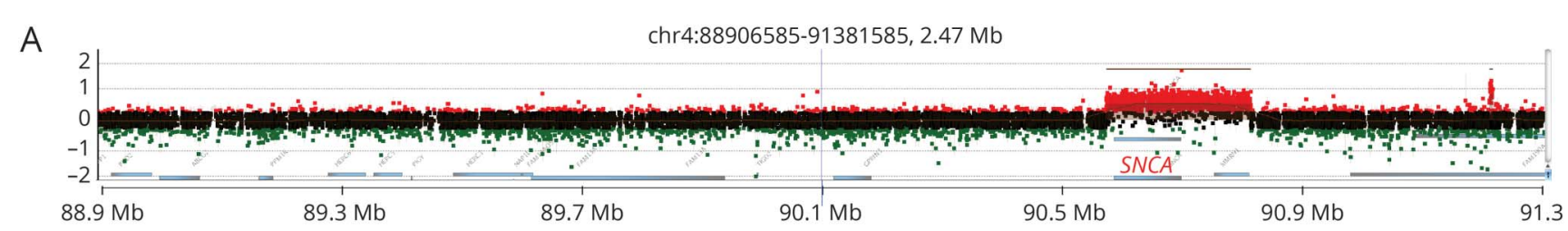

chr4:90879155-90879213(+) TTtAAAATATCAGTCTATAGTAGATCCTAGTTGTAACATGATTTCCTATTAGATTCAAA ||||||||||||||||||||||||||||||||||||||

TTTAAAATATCAGTCTATAGTAGATCCTAGTTGTTGCTTGAACCCAGGAAGCAGAGGTT | || || || || || || || || || || || || || || ||

chr4:90631166-90631224(+) ATCCCAGTCACTTGGGAGGCTGAGATAGGAGAATTGCTTGAACCCAGGAAGCAGAGGTT

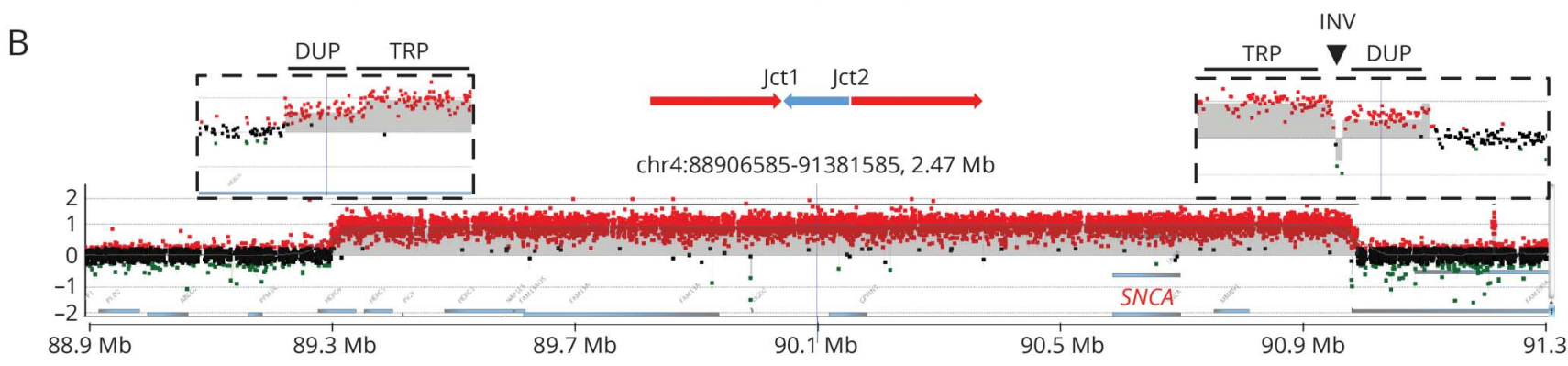

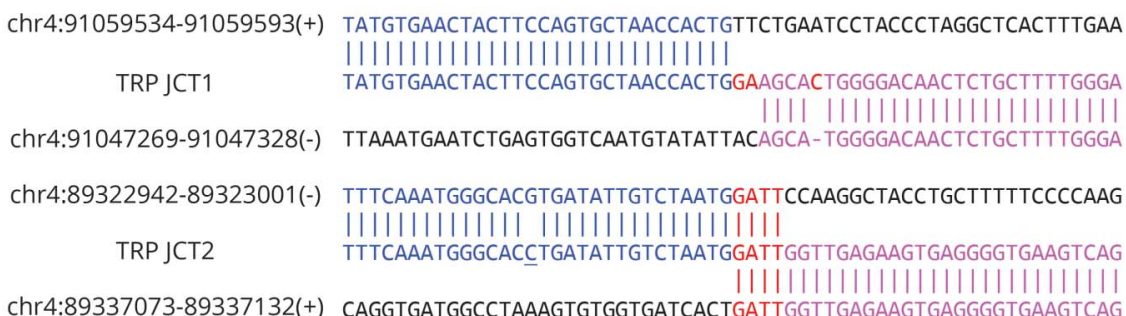

(A) In subject 3, a 248-kb duplication was identified. In this case, the whole SNCA gene was duplicated. The junction sequence (bottom) is aligned with upstream and downstream reference sequences, with the blue and pink colors indicating their different origins and the red indicating inserted nucleotides and microhomology. (B) A 1.7-Mb DUP-TRP/INV-DUP rearrangement was identified in the index subject with a known SNCA multiplication. ${ }^{17-19}$ The x-axis indicates the chromosomal regions surrounding SNCA. The $y$-axis indicates the subject vs control $\log _{2}$ ratio of the aCGH results, with duplications at 0.58 , triplications at 1 , and heterozygous deletions at -1 based on theoretical calculations. Red dots in the graph represent probes with $\log _{2}$ ratio $>0.25$, black dots with $\log _{2}$ ratio from 0.25 to -0.25 , and green dots with $\log _{2}$ ratio $<-0.25$. The normal-duplication-triplication transition regions are magnified in boxes above the plot. The entire SNCA gene is triplicated. In addition, an SNP (rs12651181, underlined) was detected close to JCT2. aCGH = array-based comparative genomic hybridization; CNV = copy number variant; DUP-TRP/INV-DUP; duplication-triplication inverted-duplication; SNP = single nucleotide polymorphism.

probands, increasing the overall genetic diagnostic yield to $19.3 \%(\mathrm{n}=21)$.

\section{Digital droplet PCR}

Given the observed high frequency of PRKN CNVs in this familial PD cohort $(\sim 5 \%)$, and the high cost of clinical-grade aCGH, we examined the feasibility of an exon-by-exon ddPCR assay to detect $P R K N$ CNVs as a proof of principle. ddPCR is an emerging cost-effective method for sensitive and reliable assessment of specific CNVs. Indeed, ddPCR revealed all PRKN CNVs detected using aCGH (subjects 6, 11, 20, 21, and 22) (figure 4A). We also interrogated an additional 92 cases from our cohort with available DNA for intragenic PRKN CNVs using ddPCR, without discovery of additional CNVs (figure 4A and figure e-2, links.lww.com/NXG/A305). We also applied ddPCR to screen for potential CNVs at the GBA locus. The 12-exon GBA shares high homology with the nearby 13exon pseudogene, GBAP1 (figure 4B). As shown in figure 4C, using ddPCR, we successfully amplified all 12 exons of GBA. Six exons $(1,2,4,7,9$, and 10) identified unique amplicons with a positive droplet ratio of 1 , whereas the other 6 exons $(3,5,6,8$, 11 , and 12) demonstrated shared amplicons with the pseudogene, resulting in a droplet ratio of 2 . Importantly, ddPCR also confirmed the deletion of GBA exons 2-8 in subject 1 (figure 4C) and did not reveal evidence for additional CNVs in 85 other samples tested (figure 4C and figure e-3, links.lww.com/ NXG/A305). Of note, ddPCR initially suggested a single exon deletion (exon 6) in subject 48; however, further investigation using Sanger sequencing revealed an intronic SNV likely degrading ddPCR amplification (figure e-4, links.lww.com/ NXG/A305). We redesigned the affected primer and demonstrated full amplification of exon 6 (e-Methods and figure e-4, links.lww.com/NXG/A305). Overall, our results suggest that ddPCR may be a sensitive and specific diagnostic tool for CNV detection in PD, including at loci such as GBA complicated by genomic regions with high sequence homology.

\section{CNV burden in clinical cohorts}

Compared with SNVs, limited reference data are available on the population frequency of CNVs, especially in 
neurologically healthy adult samples, hampering the interpretation of CNV frequencies detected in our cohort. We therefore leveraged data from the Baylor Genetics diagnostic laboratory, including 12,922 aCGH clinical referral samples. This large cohort is skewed for pediatric cases (mean age $=7.4$ years, $\mathrm{SD}=9.7$ years, range $0-79$ years), reflecting the more common use of aCGH in this population. Although the cohort includes a substantial proportion of individuals with developmental delay, autism, and dysmorphic features, there were no recorded submissions for PD. Based on stringent criteria (see e-Methods, links.lww.com/NXG/A305), at most PD loci, CNVs were either absent (DNAJC13, LRRK2, $P I N K 1$, and SNCA) or very rare at VPS35 $(\mathrm{n}=2), \mathrm{GCH} 1(\mathrm{n}=$ 1 ), and PARK7 ( $\mathrm{n}=6$, all subjects had $1 \mathrm{p} 36$ deletion syndrome). By contrast, CNVs were more common at $22 \mathrm{q} 11.2$ $(\mathrm{n}=90$, all losses affecting the critical region) and $P R K N(\mathrm{n}=$ 95). Notably, the frequency of PRKN CNVs in our PD cohort (5.1\%) represents a significant increase when compared with that of the Baylor Genetics clinical reference sample (frequency $=0.74 \%$, OR $=7.2,95 \%$ confidence interval 2.9-18.1, $\left.p=2.8 \times 10^{-5}\right)$. Because of the pseudogene, GBAP1, and suboptimal probe coverage, the array does not reliably capture GBA CNVs.

\section{Discussion}

Establishing a specific genetic diagnosis can provide information about PD risk and progression relevant to patients and their families and may soon influence treatment decisions. $^{26}$ In our familial PD sample, ES and aCGH independently identified a genetic cause for PD in $13.8 \%$ and $2.0 \%$, respectively. The diagnostic yield for ES was slightly higher than that recently reported for an early-onset PD cohort $(11.25 \%)^{8}$ and was also greater than the $10.7 \%$ diagnostic rate in an unselected adult series referred for clinical diagnostic ES. ${ }^{7}$ Given incipient treatment trials for GBA-PD and the potential importance of identifying eligible subjects in the future, ${ }^{26}$ our analyses considered lower-risk pathogenic alleles (OR 2.4), ${ }^{27}$ p.Glu365Lys and p.Thr408Met, along with higher-penetrance variants (e.g., p.Leu483Pro, OR $>5) .{ }^{28}$ Importantly, integrated ES and aCGH identified 5 additional subjects (4 unrelated probands) -including a subject with a GBA deletion-yielding an overall combined diagnostic rate of $19.3 \%$. We also uncovered numerous VUS, including SNVs within Mendelian PD genes (table e-2, links. lww.com/NXG/A306) as well as large CNVs affecting other loci (table e-4, links.lww.com/NXG/A306). Although additional evidence will be required to confirm or refute pathogenicity, our genetic diagnostic rate would nearly double if these VUS in PD genes are bona fide risk factors. Overall, our findings suggest that integrated ES and aCGH analysis is essential for routine, high-confidence genetic diagnosis in familial PD.

Most genetic diagnostic studies in PD cohorts to date have ignored the potential contribution of CNVs. Similarly, except in several notable targeted CNV studies, ${ }^{12,29}$ research-based PD gene discovery has almost exclusively focused on SNVs, using ES or genotyping arrays. Importantly, we would have missed multiple pathogenic $\mathrm{CNV}$ alleles at both autosomal dominant (SNCA and GBA) and recessive (PRKN) loci without performing aCGH. In 5 subjects, pathogenic alleles discovered at $P R K N$ would have been nondiagnostic based on isolated $\mathrm{ES}$, leading to misclassification as heterozygous carriers, whereas integrated SNV-CNV analyses successfully established the molecular diagnosis of PRKN-PD. Our findings suggest caution for interpretation of studies attributing PD risk to either PRKN CNV or SNV heterozygous carrier states in isolation, consistent with prior studies. ${ }^{30}$ Although we did not detect any CNVs at PINK1 or PARK7 in our cohort, the importance of integrated SNV-CNV analysis may

Figure 2 aCGH plot and breakpoint junction sequence of GBA deletion

A

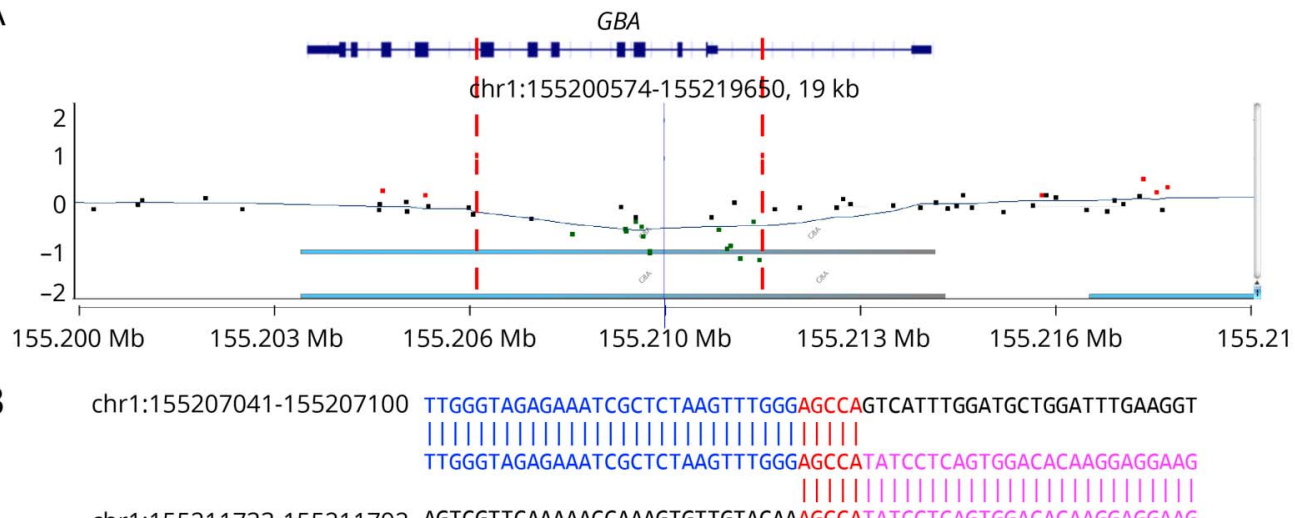

chr1:155211733-155211792 AGTCGTTCAAAAACCAAAGTGTTGTACAAAGCCATATCCTCAGTGGACACAAGGAGGAAG

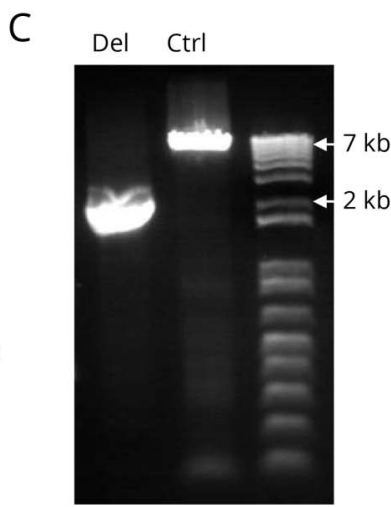

(A) aCGH plot and (B) junction sequence of a 4.7-kb deletion identified involving GBA in subject 1. The deletion (shadowed) encompasses 7 exons of GBA (from exon 2 to exon 8). (C) By agarose gel electrophoresis, the amplification of the deleted region (Del) in subject 1 showed a $\sim 5 \mathrm{~kb}$ discrepancy compared with a control (Ctl), consistent with aCGH findings. PCR showed preferential amplification of the shorter fragment in the Del lane. aCGH = array-based comparative genomic hybridization. 


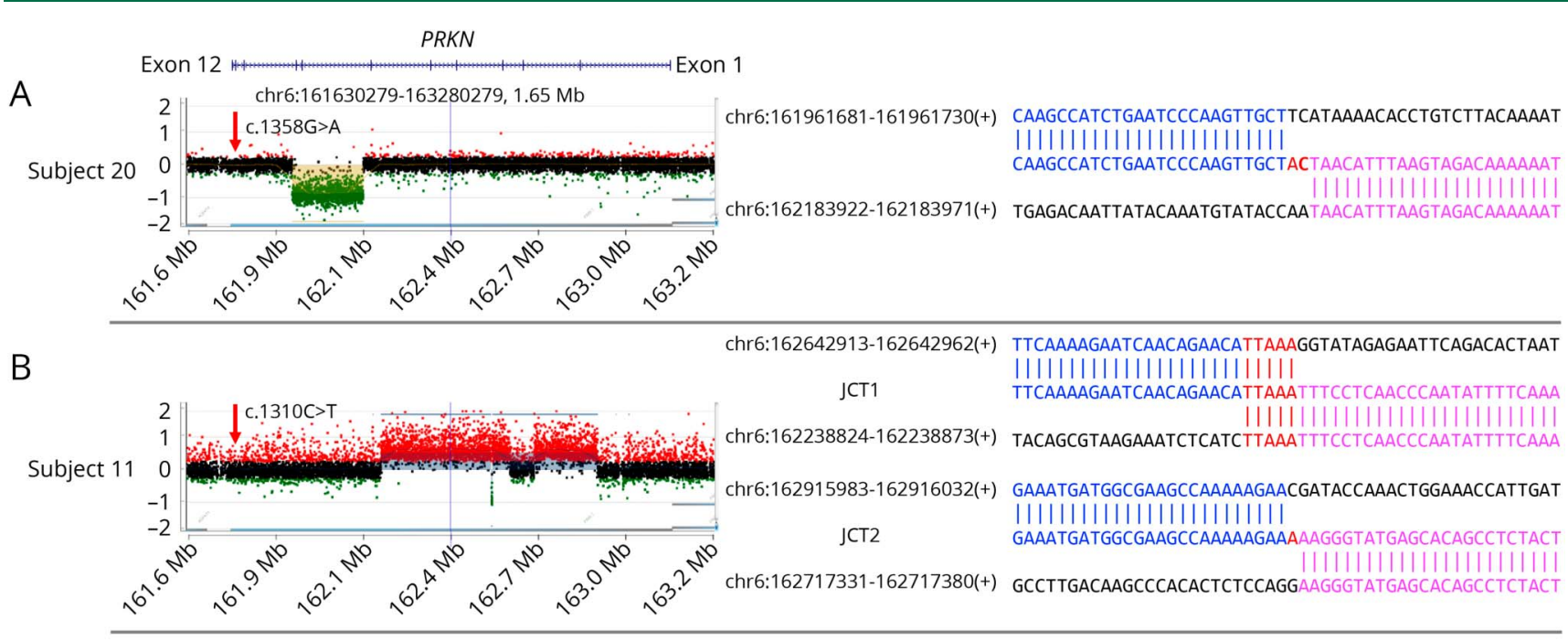

C
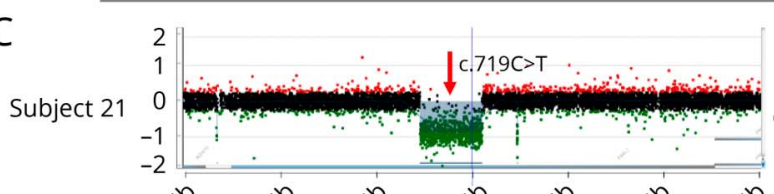

chr6:162307374-162307423(+) AACATGAAAACAAACTTCTCCAAAGTTTGTGATGTTGGCCTTGGTGCTTT

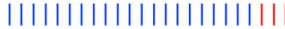

AACATGAAAACAAACTTCTCCAAATTGTCTATAGTAACCAAATACATAAA

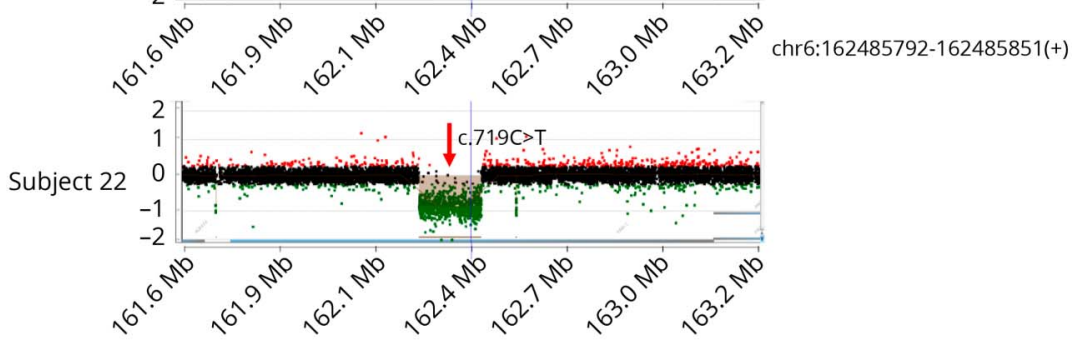

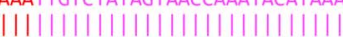
gCagggtacttTcattacatgaAattgtctatagtaAccaaatacataAa

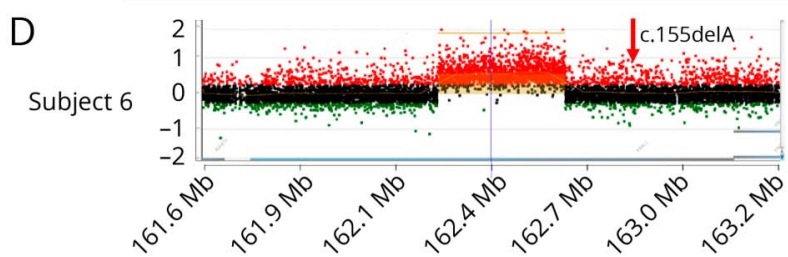

aCGH plots (left panel) and breakpoint junction sequences (right panel) of CNVs identified involving the PRKN gene in the cohort. At the top, a schematic gene structure demonstrates the 12 exons of PRKN. (A) In subject 20, a 222-kb deletion covering exons 8 and 9 was accompanied by a known pathogenic nonsense mutation c.1358G>A:p.Trp453* (gnomAD frequency = 0) in exon 12. (B) In subject 11, in addition to a missense variant c.1310C >T:p.Pro437Leu (exon 12), a duplication-normal-duplication (DUP-NML-DUP) was identified. (C) Siblings 21 and 22 share a pathogenic missense variant c.719C>T:p.Thr240Met (in exon 6) and a 178-kb deletion (disrupting exons 5 and 6). (D) In subject 6, a 364-kb duplication encompassed exons 4 to 6 . A known pathogenic frameshift variant c. 155delA:p.Asn52Metfs* 29 was identified in exon 2 (gnomAD frequency $\left.=2.5 \times 10^{-4}\right)$. Breakpoint sequencing was not successful in this sample. aCGH $=$ arraybased comparative genomic hybridization; CNV = copy number variant; gnomAD = Genome Aggregation Database .

extend to other autosomal recessive PD loci besides PRKN. Because our CNV and SNV data are unphased, and parental genotypes are not available, we cannot definitively exclude the possibility that certain CNVs and SNVs at PRKN were in cisrather than trans-configuration. Nevertheless, our data suggest that structural variants may co-occur with SNVs more commonly than previously recognized, making consideration of both allele types important for comprehensive genetic diagnosis in PD.

ES has significantly accelerated the scope of gene discovery in PD and other neurologic disorders, but remains insensitive to allele classes such as trinucleotide repeat expansions and
CNVs. Although bioinformatic tools may help identify CNVs from ES data, available algorithms have high false-positive rates when compared with $\mathrm{aCGH}^{31}$ and this method may miss up to $30 \%$ of clinically relevant CNVs. ${ }^{11}$ To our knowledge, genome-wide aCGH with exon-by-exon coverage has not been previously applied in PD. Limitations of aCGH include significant cost and the possibility of missing small deletions/duplications. Alternative methods, such as ddPCR, may offer a cost-effective alternative for screening specific genes, $^{32}$ including for small CNVs. In our study, ddPCR showed high sensitivity and specificity for detection of CNVs at both PRKN and GBA. Moreover, ddPCR successfully differentiated copy number changes affecting exons unique to 


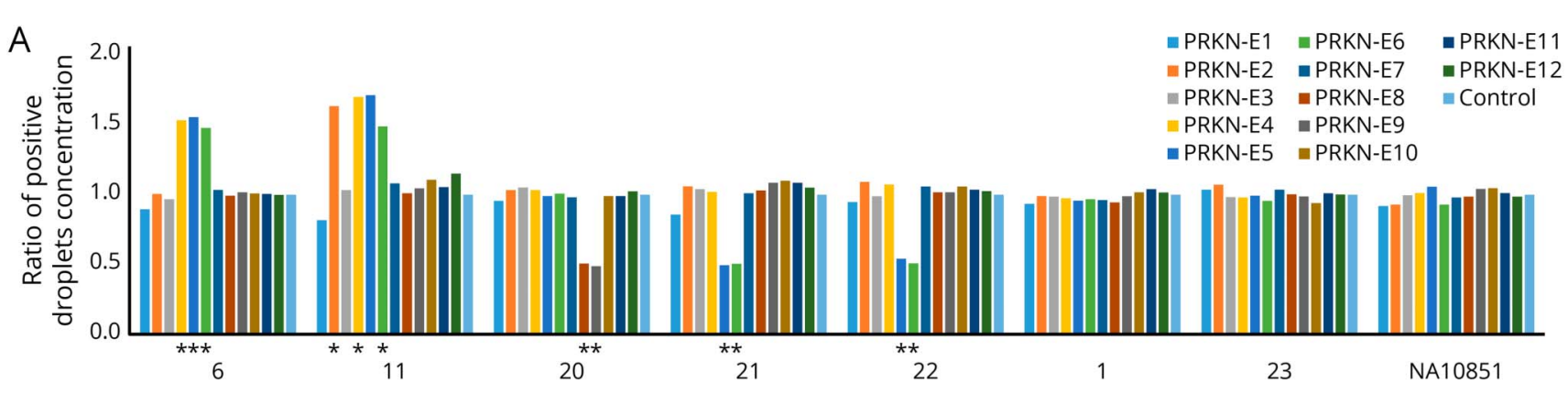

B

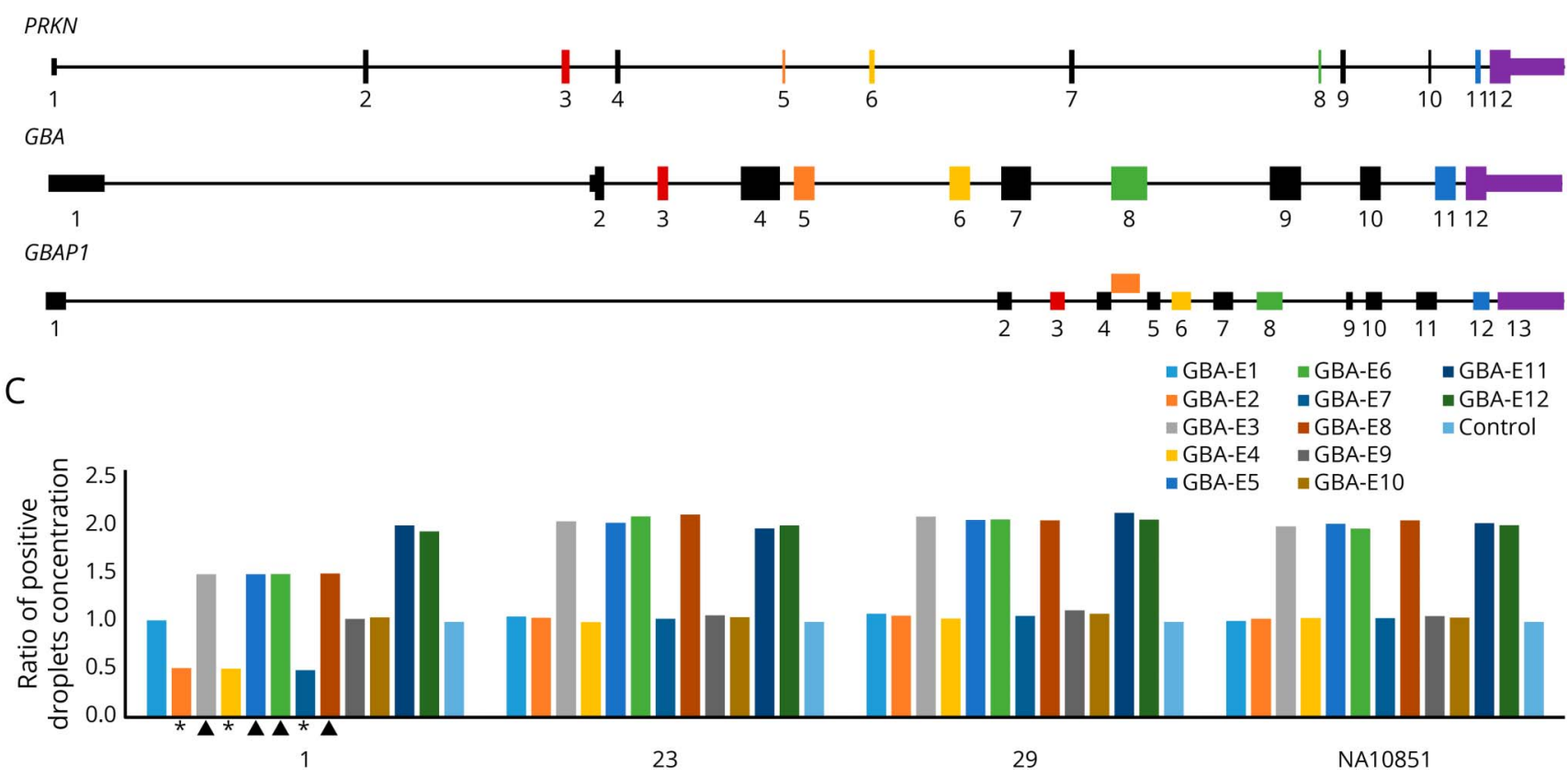

(A) Positive droplet concentrations in 8 subjects. Primer pairs for the 12 exons of PRKN and 2 control genes, RPPH1 and TERT, were used to obtain positive droplet concentrations from PCR in each individual (e-Methods and figure e-4A, links.Iww.com/NXG/A305). The y-axis shows exon-by-exon results in 13 columns with different colors, showing comparable results to the average value of RPPH1 and TERT. A y-axis value of 0.5 indicates a deletion, 1 copy neutral (no deletion, no duplication), and 1.5 a duplication. In subject 6 , a duplication involving exons 4 to 6 was identified as shown by aCGH; in subject 11 , exons 2 , 4, 5 , and 6 demonstrated copy number gains; in subject 20, there is a copy number loss involving exons 8 and 9 ; similarly, in subjects 21 and 22 a copy number loss of exons 5 and 6 is detected. In subjects 1, 23, and HapMap NA10851, no amplicons showed altered copy number. See also figure e-2 (links.Iww.com/NXG/ A305). Copy number variants are denoted with asterisks (*). (B) GBA and its nearby pseudogene, GBAP1, share a high degree of sequence homology, with ddPCR primer pairs for 6 of the 12 exons of GBA producing amplicons concurrently from GBA and GBAP1. GBA exons $3,5,6,8,11$, and 12 are color coded to demonstrate their homologous regions within GBAP1, which result in a doubling of the apparent copy number identified by ddPCR: 4 instead of 2 copies (ratio $=2$ ), indicate copy number neutrality for these exons. GBA exon 5 is homologous with an intragenic region between exons 4 and 5 of GBAP1. (C) ddPCR detected potential exonic CNVs in GBA. Here, we demonstrate a deletion identified in subject 1, compared with HapMap subject NA10581 and other 2 subjects, ratios of exons 2 to 8 were each reduced by 0.5 -fold, consistent with a deletion involving these exons. Deleted exons are denoted with an asterisk ( ${ }^{*}$ ); deleted exons with a droplet ratio of 1.5 due to GBAP1 amplification are denoted with an arrowhead. See also figure e-3 (links.Iww.com/NXG/A305). aCGH = array-based comparative genomic hybridization; CNV = copy number variant; ddPCR = droplet digital PCR.

GBA avoiding potential confounding by the adjacent pseudogene, GBAP1.

Despite evidence of an important role in disease risk, the mechanism(s) for generating CNVs relevant to $\mathrm{PD}$ remain largely unknown. Broadly, CNVs may form through mechanisms associated with DNA recombination, DNA replication, and/or DNA repair. ${ }^{20}$ Nonallelic homologous recombination can result in recurrent rearrangements. In contrast, nonhomologous end joining, ${ }^{20}$ fork stalling and template switching (FoSTeS) and microhomology-mediated breakinduced replication (MMBIR), ${ }^{21}$ lead to nonrecurrent CNVs.
In our study, all junction breakpoint sequencing results were consistent with the FoSTeS/MMBIR mechanism, including for CNV alleles discovered at SNCA, PRKN, and GBA. These results are consistent with a recent analysis of SNCA duplications from 6 independent cases. ${ }^{33}$ These findings have important implications for screening assays because the detection of nonrecurrent $\mathrm{CNV}$ s requires methods sensitive for heterogeneous, exon-by-exon changes. The FoSTeS/MMBIR mechanism can also trigger multiple iterative template switches in a single event, leading to the generation of more complex genomic rearrangements. Breakpoint sequencing of an SNCA CNV first observed in the Spellman-Muenter/Iowa 
kindred $^{18,19}$ confirmed the DUP-TRP-DUP structure ${ }^{23}$ and further revealed an internal inversion (DUP-TRP/INVDUP) and microhomology. This rearrangement must have arisen during mitosis via $\mathrm{FoSTeS} / \mathrm{MMBIR}^{20}$ and therefore likely represents a de novo triplication, in contrast to the meiotic PMP22 triplications observed in Charcot-MarieTooth (MIM\#118220), which derives from a duplication in the previous generation. ${ }^{34}$ Our results therefore demonstrate the essential role of breakpoint junction sequencing in definitively resolving $\mathrm{CNV}$ structure and responsible mechanisms.

Deletions in GBA rarely contribute to autosomal recessive Gaucher disease (MIM\#230800). ${ }^{35}$ Our discovery of a GBA deletion allele in a subject with $\mathrm{PD}$, expected to cause glucocerobrosidase haploinsufficiency, adds to other emerging evidence supporting a loss-of-function mechanism in GBA$\mathrm{PD}^{36}$ It will be informative to screen for additional GBA CNVs in additional case/control cohorts-perhaps using ddPCR - to determine how commonly these alleles are associated with PD risk and estimate their effect size and penetrance. We also identified 2 subjects doubly heterozygous for SNVs in both GBA and LRRK2, consistent with prior reports. ${ }^{37}$ We expect that additional PD cases compatible with oligogenic inheritance models will emerge following widespread adoption of comprehensive, genome-wide diagnostic approaches, including ES and aCGH. Future studies must address how such alleles may interact to modify PD risk and/ or clinical manifestations. Finally, although our study focused on pathogenic alleles in established Mendelian loci, future assessment of a more complete spectrum of genetic variation through integrated SNV-CNV analysis is also likely to enhance power for novel PD gene discovery.

\section{Acknowledgment}

The authors thank all the families who participated in this study. They also thank Dr. Dennis W. Dickson and Dr. Zbigniew Wszolek (Mayo Clinic, Jacksonville, FL) for providing the SNCA-positive control sample. They also acknowledge Anita Kaw (Baylor College of Medicine, Houston, TX) for help with sample preparation and Mitchell A. Rao and Ido Machol (Baylor Genetics, Houston, TX) for data retrieval from the clinical database.

\section{Study funding}

This work was supported in part by The American Academy of Neurology (L.A.R.), Baylor College of Medicine Medical Genetics Research Fellowship T32 GM07526 (L.A.R.), NINDS K08 NS112467 (L.A.R.), the Baylor-Hopkins Center for Mendelian Genomics, BHCMG (UM1 HG006542 to J.R.L.), which is jointly funded by the National Human Genome Research Institute (NHGRI), National Heart Lung and Blood Institute (NHLBI), and NINDS R35 NS105078 (J.R.L.). J.E.P. was supported by NHGRI K08 HG008986. J.M.S. was supported by grants from the Huffington Foundation, Jan and Dan Duncan Neurological Research Institute at Texas Children's Hospital, and a Career Award for Medical
Scientists from the Burroughs Wellcome Fund. The Mayo Clinic Brain Bank is supported by the Mangurian Foundation Lewy Body Dementia Program at Mayo Clinic.

\section{Disclosure}

L.A. Robak, R. Du, B. Yuan, S. Gu, I. Alfradique-Dunham, V. Kondapalli, E. Hinojosa, A. Stillwell, E. Young, C. Zhang, X. Song, H. Du, T. Gambin, S.N. Jhangiani, Z. Coban Akdemir, D.M. Muzny, A. Tejomurtula, O.A. Ross, C. Shaw, J. Jankovic, W. Bi, and J.E. Posey report no disclosures relevant to the manuscript. J.R. Lupski has stock ownership in 23andMe and Lasergen and is a paid consultant for Regeneron and a coinventor on multiple US and European patents related to molecular diagnostics for inherited neuropathies, eye diseases, and bacterial genomic fingerprinting. J.M. Shulman consults for the Adrienne Helis Malvin \& Diana Helis Henry Medical Research Foundations. Go to Neurology.org/NG for full disclosures.

\section{Publication history}

Received by Neurology: Genetics December 27, 2019. Accepted in final form June 15, 2020.

\begin{tabular}{lll} 
Appendix Authors & \\
\hline Name & Location & Contribution \\
\hline $\begin{array}{l}\text { Laurie A. } \\
\text { Robak, MD, } \\
\text { PhD }\end{array}$ & $\begin{array}{l}\text { Baylor College of } \\
\text { Medicine, } \\
\text { Houston, TX }\end{array}$ & $\begin{array}{l}\text { Conceptualization, investigation, } \\
\text { data generation, data analysis, } \\
\text { data curation, writing-original } \\
\text { draft, and writing-review and } \\
\text { editing }\end{array}$ \\
\hline $\begin{array}{l}\text { Renqian Du, } \\
\text { PhD, DDS }\end{array}$ & $\begin{array}{l}\text { Baylor College of } \\
\text { Medicine, } \\
\text { Houston, TX }\end{array}$ & $\begin{array}{l}\text { Conceptualization, investigation, } \\
\text { data generation, data analysis, } \\
\text { data curation, writing-original } \\
\text { draft, and writing-review and } \\
\text { editing }\end{array}$
\end{tabular}

\begin{tabular}{lll}
\hline Bo Yuan, PhD & $\begin{array}{l}\text { Baylor College of } \\
\text { Medicine, } \\
\text { Houston, TX }\end{array}$ & $\begin{array}{l}\text { Conceptualization, investigation, } \\
\text { data generation, data analysis, } \\
\text { data curation, and } \\
\text { writing-review and editing }\end{array}$ \\
\hline Shen Gu, PhD & $\begin{array}{l}\text { Baylor College of } \\
\text { Medicine, } \\
\text { Houston, TX }\end{array}$ & $\begin{array}{l}\text { Conceptualization, investigation, } \\
\text { data generation, data analysis, } \\
\text { data curation, and } \\
\text { writing-review and editing }\end{array}$ \\
\hline $\begin{array}{l}\text { Isabel } \\
\text { Alfradique- } \\
\text { Dunham, MD }\end{array}$ & $\begin{array}{l}\text { Baylor College of } \\
\text { Medicine, }\end{array}$ & $\begin{array}{l}\text { Data curation and } \\
\text { writing-review and editing }\end{array}$ \\
\hline $\begin{array}{l}\text { Vismaya } \\
\text { Kondapalli, BS }\end{array}$ & $\begin{array}{l}\text { Baylor College of } \\
\text { Medicine, } \\
\text { Houston, TX }\end{array}$ & $\begin{array}{l}\text { Data generation, } \\
\text { writing-original draft, and } \\
\text { writing-review and editing }\end{array}$ \\
\hline $\begin{array}{l}\text { Evelyn } \\
\text { Hinojosa, BS }\end{array}$ & $\begin{array}{l}\text { Baylor College of } \\
\text { Medicine, } \\
\text { Houston, TX }\end{array}$ & $\begin{array}{l}\text { Data curation and } \\
\text { writing-review and editing }\end{array}$ \\
\hline $\begin{array}{l}\text { Amanda } \\
\text { Stillwell, BS }\end{array}$ & $\begin{array}{l}\text { Baylor College of } \\
\text { Medicine, } \\
\text { Houston, TX }\end{array}$ & $\begin{array}{l}\text { Data curation and } \\
\text { writing-review and editing }\end{array}$ \\
\hline $\begin{array}{l}\text { Emily Young, } \\
\text { BA }\end{array}$ & $\begin{array}{l}\text { Baylor College of } \\
\text { Medicine, } \\
\text { Houston, TX }\end{array}$ & $\begin{array}{l}\text { Data curation and } \\
\text { writing-review and editing }\end{array}$ \\
\hline
\end{tabular}


Appendix (continued)

\begin{tabular}{|c|c|c|}
\hline Name & Location & Contribution \\
\hline $\begin{array}{l}\text { Chaofan } \\
\text { Zhang, BS }\end{array}$ & $\begin{array}{l}\text { Baylor College of } \\
\text { Medicine, } \\
\text { Houston, TX }\end{array}$ & $\begin{array}{l}\text { Data generation and } \\
\text { writing-review and editing }\end{array}$ \\
\hline $\begin{array}{l}\text { Xiaofei Song, } \\
\text { PhD }\end{array}$ & $\begin{array}{l}\text { Baylor College of } \\
\text { Medicine, } \\
\text { Houston, TX }\end{array}$ & $\begin{array}{l}\text { Data generation and } \\
\text { writing-review and editing }\end{array}$ \\
\hline $\begin{array}{l}\text { Haowei Du, } \\
\text { MS }\end{array}$ & $\begin{array}{l}\text { Baylor College of } \\
\text { Medicine, } \\
\text { Houston, TX }\end{array}$ & $\begin{array}{l}\text { Data generation and } \\
\text { writing-review and editing }\end{array}$ \\
\hline $\begin{array}{l}\text { Tomasz } \\
\text { Gambin, PhD }\end{array}$ & $\begin{array}{l}\text { Baylor College of } \\
\text { Medicine, } \\
\text { Houston, TX }\end{array}$ & $\begin{array}{l}\text { Data analysis and } \\
\text { writing-review and editing }\end{array}$ \\
\hline $\begin{array}{l}\text { Shalini N. } \\
\text { Jhangiani, } \\
\text { PhD }\end{array}$ & $\begin{array}{l}\text { Baylor Genetics, } \\
\text { Houston, TX }\end{array}$ & $\begin{array}{l}\text { Data generation and } \\
\text { writing-review and editing }\end{array}$ \\
\hline $\begin{array}{l}\text { Zeynep Coban } \\
\text { Akdemir, PhD }\end{array}$ & $\begin{array}{l}\text { Baylor College of } \\
\text { Medicine, } \\
\text { Houston, TX }\end{array}$ & $\begin{array}{l}\text { Data analysis, methodology, and } \\
\text { writing-review and editing }\end{array}$ \\
\hline $\begin{array}{l}\text { Donna M. } \\
\text { Muzny, MS }\end{array}$ & $\begin{array}{l}\text { Baylor Genetics, } \\
\text { Houston, TX }\end{array}$ & $\begin{array}{l}\text { Data generation and } \\
\text { writing-review and editing }\end{array}$ \\
\hline $\begin{array}{l}\text { Anusha } \\
\text { Tejomurtula, } \\
\text { MS }\end{array}$ & $\begin{array}{l}\text { Baylor College of } \\
\text { Medicine, } \\
\text { Houston, TX }\end{array}$ & $\begin{array}{l}\text { Data generation and } \\
\text { writing-review and editing }\end{array}$ \\
\hline $\begin{array}{l}\text { Owen A. Ross, } \\
\text { PhD }\end{array}$ & $\begin{array}{l}\text { Mayo Clinic, } \\
\text { Jacksonville, FL }\end{array}$ & $\begin{array}{l}\text { Writing_review and editing and } \\
\text { resources }\end{array}$ \\
\hline $\begin{array}{l}\text { Chad Shaw, } \\
\text { PhD }\end{array}$ & $\begin{array}{l}\text { Baylor College of } \\
\text { Medicine, } \\
\text { Houston, TX }\end{array}$ & $\begin{array}{l}\text { Data curation and } \\
\text { writing-review and editing }\end{array}$ \\
\hline $\begin{array}{l}\text { Joseph } \\
\text { Jankovic, MD }\end{array}$ & $\begin{array}{l}\text { Baylor College of } \\
\text { Medicine, } \\
\text { Houston, TX }\end{array}$ & $\begin{array}{l}\text { Data curation, writing-review } \\
\text { and editing, resources, and } \\
\text { supervision }\end{array}$ \\
\hline $\begin{array}{l}\text { Weimin Bi, } \\
\text { PhD }\end{array}$ & $\begin{array}{l}\text { Baylor College of } \\
\text { Medicine, } \\
\text { Houston, TX }\end{array}$ & $\begin{array}{l}\text { Data curation writing-review } \\
\text { and editing, and supervision }\end{array}$ \\
\hline $\begin{array}{l}\text { Jennifer E. } \\
\text { Posey, MD, } \\
\text { PhD }\end{array}$ & $\begin{array}{l}\text { Baylor College of } \\
\text { Medicine, } \\
\text { Houston, TX }\end{array}$ & $\begin{array}{l}\text { Data analysis, data curation, } \\
\text { writing-original draft, } \\
\text { writing-review and editing, and } \\
\text { supervision }\end{array}$ \\
\hline $\begin{array}{l}\text { James R. } \\
\text { Lupski, MD, } \\
\text { PhD }\end{array}$ & $\begin{array}{l}\text { Baylor College of } \\
\text { Medicine, } \\
\text { Houston, TX }\end{array}$ & $\begin{array}{l}\text { Conceptualization, } \\
\text { writing-review and editing, } \\
\text { resources, and supervision }\end{array}$ \\
\hline $\begin{array}{l}\text { Joshua M. } \\
\text { Shulman, MD, } \\
\text { PhD }\end{array}$ & $\begin{array}{l}\text { Baylor College of } \\
\text { Medicine, } \\
\text { Houston, TX }\end{array}$ & $\begin{array}{l}\text { Conceptualization, } \\
\text { writing-original draft, } \\
\text { writing-review and editing, } \\
\text { resources, and supervision }\end{array}$ \\
\hline
\end{tabular}

\section{References}

1. Elbaz A, Grigoletto F, Baldereschi M, et al. Familial aggregation of Parkinson's disease: a population-based case-control study in Europe. EUROPARKINSON Study Group. Neurology 1999;52:1876-1882.

2. Karimi-Moghadam A, Charsouei S, Bell B, Jabalameli MR. Parkinson disease from Mendelian forms to genetic susceptibility: new molecular insights into the neurodegeneration process. Cell Mol Neurobiol 2018;38:1153-1178.

3. Espay AJ, Brundin P, Lang AE. Precision medicine for disease modification in Parkinson disease. Nat Rev Neurol 2017;13:119-126.
4. Falcone DC, Wood EM, Xie SX, Siderowf A, Van Deerlin VM. Genetic testing and Parkinson disease: assessment of patient knowledge, attitudes, and interest. J Genet Couns 2011;20:384-395.

5. Brás J, Guerreiro R, Hardy J. SnapShot: genetics of Parkinson’s disease. Cell 2015 160:570-570.e1

6. Hernandez DG, Reed X, Singleton AB. Genetics in Parkinson disease: Mendelian versus non-Mendelian inheritance. J Neurochem 2016;139(suppl 1):59-74.

7. Posey JE, Rosenfeld JA, James RA, et al. Molecular diagnostic experience of wholeexome sequencing in adult patients. Genet Med 2016;18:678-685.

8. Schormair B, Kemlink D, Mollenhauer B, et al. Diagnostic exome sequencing in earlyonset Parkinson's disease confirms VPS13C as a rare cause of autosomal-recessive Parkinson's disease. Clin Genet 2018;93:603-612.

9. La Cognata V, Morello G, D’Agata V, Cavallaro S. Copy number variability in Parkinson's disease: assembling the puzzle through a systems biology approach. Hum Genet 2017;136:13-37.

10. Gambin T, Akdemir ZC, Yuan B, et al. Homozygous and hemizygous CNV detection from exome sequencing data in a Mendelian disease cohort. Nucleic Acids Res 2017; 45:1633-1648.

11. Dharmadhikari AV, Ghosh R, Yuan B, et al. Copy number variant and runs of homozygosity detection by microarrays enabled more precise molecular diagnoses in 11,020 clinical exome cases. Genome Med 2019;11:30.

12. Pankratz N, Dumitriu A, Hetrick KN, et al. Copy number variation in familial Parkinson disease. PLoS One 2011;6:e20988.

13. Simon-Sanchez J, Scholz S, del Mar Matarin M, et al. Genomewide SNP assay reveals mutations underlying Parkinson disease. Hum Mutat 2008;29:315-322.

14. Wiszniewska J, Bi W, Shaw C, et al. Combined array CGH plus SNP genome analyses in a single assay for optimized clinical testing. Eur J Hum Genet 2014;22:79-87.

15. Cheung SW, Shaw CA, Yu W, et al. Development and validation of a CGH microarray for clinical cytogenetic diagnosis. Genet Med 2005;7:422-432.

16. Härmälä SK, Butcher R, Roberts $\mathrm{CH}$. Copy number variation analysis by droplet digital PCR. Methods Mol Biol 2017;1654:135-149.

17. Singleton $A B$, Farrer $M$, Johnson J, et al. alpha-Synuclein locus triplication causes Parkinson's disease. Science 2003;302:841.

18. Spellman GG. Report of familial cases of parkinsonism. Evidence of a dominant trait in a patient's family. JAMA 1962;179:372-374.

19. Muenter MD, Forno LS, Hornykiewicz O, et al. Hereditary form of parkinsonism: dementia. Ann Neurol 1998;43:768-781.

20. Carvalho CMB, Lupski JR. Mechanisms underlying structural variant formation in genomic disorders. Nat Rev Genet 2016;17:224-238.

21. Zhang F, Khajavi M, Connolly AM, Towne CF, Batish SD, Lupski JR. The DNA replication FoSTeS/MMBIR mechanism can generate genomic, genic and exonic complex rearrangements in humans. Nat Genet 2009;41:849-853.

22. Beck CR, Carvalho CMB, Akdemir ZC, et al. Megabase length hypermutation accompanies human structural variation at 17p11.2. Cell 2019;176:1310-1324.e10.

23. Zafar F, Valappil RA, Kim S, et al. Genetic fine-mapping of the Iowan SNCA gene triplication in a patient with Parkinson's disease. NPJ Parkinsons Dis 2018;4:18.

24. Carvalho CMB, Ramocki MB, Pehlivan $\mathrm{D}$, et al. Inverted genomic segments and complex triplication rearrangements are mediated by inverted repeats in the human genome. Nat Genet 2011;43:1074-1081.

25. Deng H, Le W-D, Hunter CB, et al. Heterogeneous phenotype in a family with compound heterozygous parkin gene mutations. Arch Neurol 2006;63:273-277.

26. Espay AJ, Brundin P, Lang AE. Precision medicine for disease modification in Parkinson disease. Nat Rev Neurol 2017;13:119-126.

27. Benitez BA, Davis AA, Jin SC, et al. Resequencing analysis of five Mendelian genes and the top genes from genome-wide association studies in Parkinson's disease. Mol Neurodegener 2016;11:29.

28. Sidransky E, Nalls MA, Aasly JO, et al. Multicenter analysis of glucocerebrosidase mutations in Parkinson's disease. N Engl J Med 2009;361:1651-1661.

29. Kim JS, Yoo JY, Lee KS, et al. Comparative genome hybridization array analysis for sporadic Parkinson's disease. Int J Neurosci 2008;118:1331-1345.

30. Kay DM, Stevens CF, Hamza TH, et al. A comprehensive analysis of deletions, multiplications, and copy number variations in PARK2. Neurology 2010;75:1189-1194.

31. de Ligt J, Boone PM, Pfundt R, et al. Detection of clinically relevant copy number variants with whole-exome sequencing. Hum Mutat 2013;34:1439-1448.

32. Gu S, Posey JE, Yuan B, et al. Mechanisms for the generation of two quadruplications associated with split-hand malformation. Hum Mutat 2016;37:160-164.

33. Seo SH, Bacolla A, Yoo D, et al. Replication-based rearrangements are a common mechanism for SNCA duplication in Parkinson's disease. Mov Disord 2020;35:868-876

34. Liu P, Gelowani V, Zhang F, et al. Mechanism, prevalence, and more severe neuropathy phenotype of the Charcot-Marie-Tooth type 1A triplication. Am J Hum Genet 2014;94:462-469.

35. Beutler E, Gelbart T, West C. Identification of six new Gaucher disease mutations. Genomics 1993;15:203-205.

36. Ysselstein D, Shulman JM, Krainc D. Emerging links between pediatric lysosomal storage diseases and adult parkinsonism. Mov Disord 2019;34:614-624.

37. Yahalom G, Greenbaum L, Israeli-Korn S, et al. Carriers of both GBA and LRRK2 mutations, compared to carriers of either, in Parkinson's disease: risk estimates and genotype-phenotype correlations. Parkinsonism Relat Disord 2019;62:179-184. 


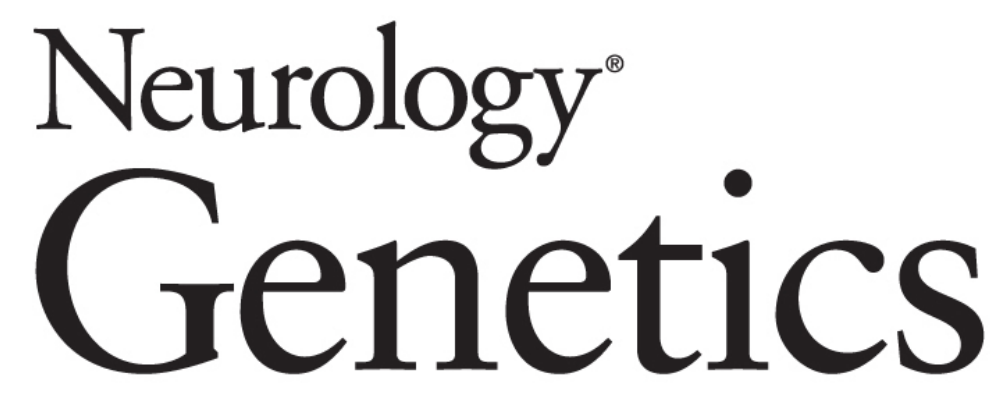

\section{Integrated sequencing and array comparative genomic hybridization in familial Parkinson disease}

Laurie A. Robak, Renqian Du, Bo Yuan, et al.

Neurol Genet 2020;6;

DOI 10.1212/NXG.0000000000000498

This information is current as of July 28,2020

\section{Updated Information \&} Services

References

Permissions \& Licensing

Reprints including high resolution figures, can be found at: http://ng.neurology.org/content/6/5/e498.full.html

This article cites 37 articles, 1 of which you can access for free at: http://ng.neurology.org/content/6/5/e498.full.html\#\#ref-list-1

Information about reproducing this article in parts (figures,tables) or in its entirety can be found online at:

http://ng.neurology.org/misc/about.xhtml\#permissions

Information about ordering reprints can be found online: http://ng.neurology.org/misc/addir.xhtml\#reprintsus

Neurol Genet is an official journal of the American Academy of Neurology. Published since April 2015, it is an open-access, online-only, continuous publication journal. Copyright Copyright $\odot 2020$ The Author(s). Published by Wolters Kluwer Health, Inc. on behalf of the American Academy of Neurology.. All rights reserved. Online ISSN: 2376-7839.

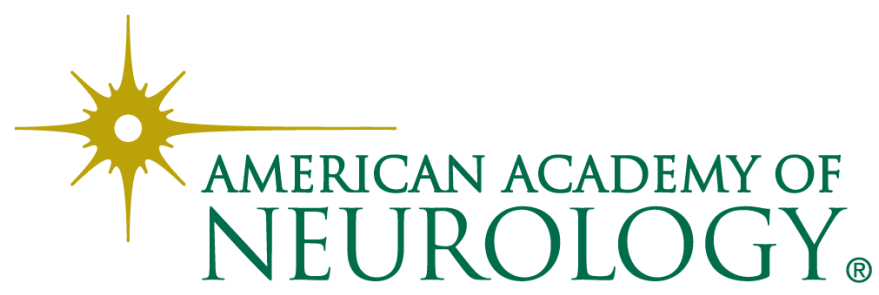

